\title{
Mysteriously puffy hand: puffy hand syndrome
}

\author{
Yasmin Aghajan, Joseph Diaz, Emily Sladek
}

Department of Internal Medicine, UC San Diego, La Jolla, California, USA

\section{Correspondence to}

Dr Yasmin Aghajan, yaghajan@ucsd.edu

Accepted 28 November 2018

\section{DESCRIPTION}

A 59-year-old man with a history of intravenous drug use (DU) presented with a 3-day history of right-hand swelling, redness, warmth and pain. Physical examination was notable for a tensely oedematous hand with non-pitting oedema, warmth, blanching erythema and decreased range of motion (figure 1). He was empirically started on intravenous vancomycin for presumed skin and

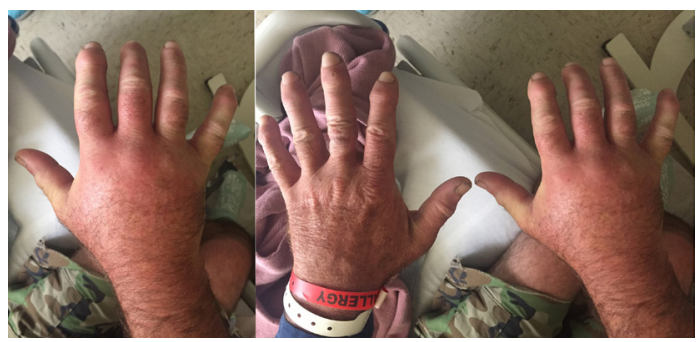

Figure 1 Oedematous, erythematous and warm right hand with appearance similar to a typical presentation of cellulitis/SSTI or deep vein thrombosis. In comparison, the left hand is normal. The dorsal aspect of the hand is more affected. SSTI, skin and soft-tissue infection.

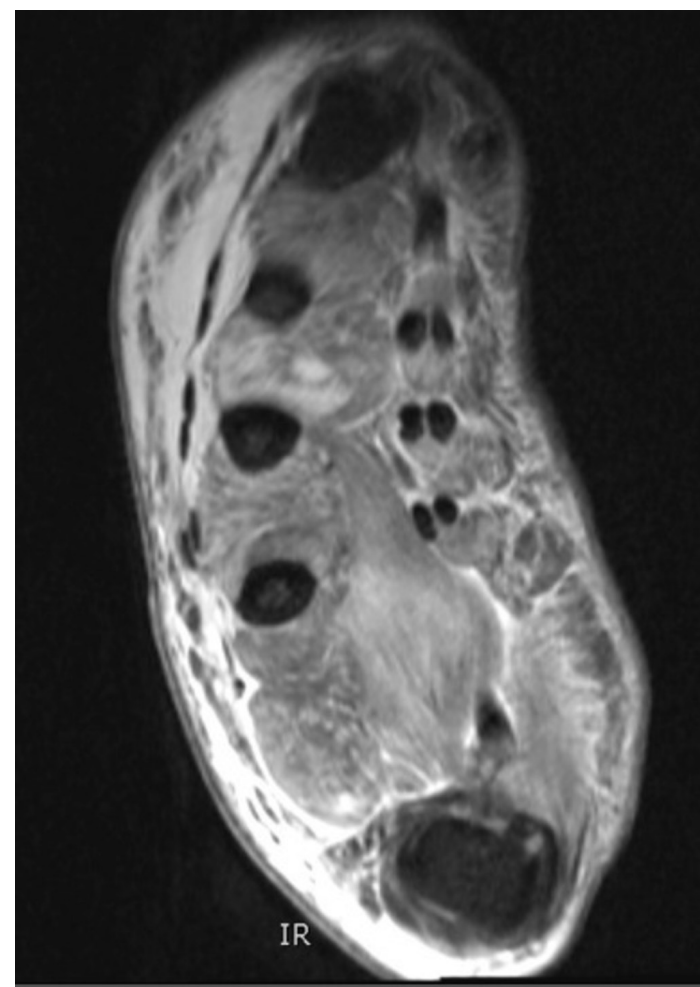

Figure 2 MRI T2-weighted axial of the hand demonstrates diffuse myositis and oedema of the intrinsic hand muscles, sparing the tendons and without any abnormal marrow changes. soft-tissue infection (SSTI). The patient was afebrile and studies including $\mathrm{C}$ reactive protein, leucocyte count and blood cultures were normal. An ultrasound study did not reveal any deep vein thrombosis. X-rays showed no fracture, foreign bodies or gas formation. There was no improvement after 48 hours of antibiotic therapy. MRI of the hand showed diffuse myositis of the intrinsic hand muscles and surrounding skin oedema (figures 2 and 3). Initially, he denied intravenous drug use into his arms, however, on further questioning, the patient admitted to injecting methamphetamine. Although he denied recent use, urine toxicology was positive for amphetamines. He had previously been taking buprenorphine through addiction clinic, but denied injecting it into his hands. Given the lack of serum inflammatory/infectious markers, lack of clinical improvement on antibiotics, the

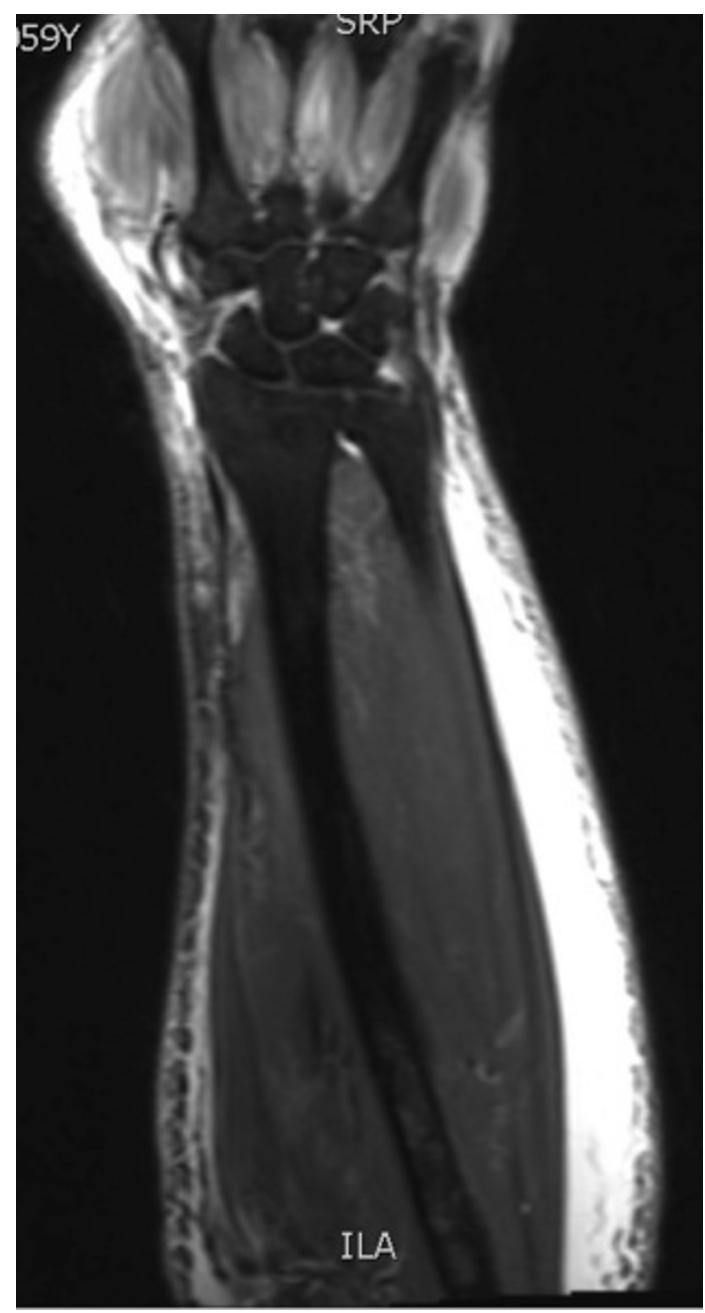

Figure 3 T2-weighted MRI of the forearm redemonstrates oedema of the hand muscles and oedema of the skin and subcutaneous tissue of the forearm. 
diagnosis of puffy hand syndrome was made. Oedema, erythema and pain improved after 48 hours of upper extremity elevation in a Murphy sling and resolved completely after 96 hours.

The differential diagnosis of the single swollen extremity includes SSTI (especially in patients with history of intravenous DU), osteomyelitis, deep vein thrombosis, arterial thrombosis and trauma. Puffy hand syndrome is a lesser-known complication of long-term intravenous DU and may affect about $7 \%-16 \%$ of intravenous drug users. ${ }^{1}$ It may present after periods of intermittent painless oedema which finally becomes permanent. Presentation may be delayed years after the reported last intravenous DU. Oedema is non-pitting, and typically affects the dorsal hand and fingers. Presentation may be complicated by superimposed infection. ${ }^{1}$ One study confirmed that injections in the hands were associated with puffy hand syndrome in intravenous DU. ${ }^{2}$ The pathophysiology of puffy hand syndrome is thought to involve venous and lymphatic insufficiency, as repeated injections result in sclerosis of veins and lymphatic vessels. The syndrome has especially been linked to buprenorphine injections. The diagnosis can be made clinically or with lymphoscintigraphy. Unfortunately, there are no specific treatments, however, some studies suggest the use of low-stretch bandages may help. ${ }^{3}$ In our case, the syndrome resolved after several days of elevation and compression bandage use.

In summary, while it is essential to rule out infection, deep vein thrombosis and other more common causes of a swollen extremity, our case highlights a lesser-known complication of intravenous DU. Although data are sparse on puffy hand syndrome, patients may benefit from traditional lymphoedema treatments including compression bandaging and garments, intermittent pneumatic compression, physical therapy and referral to specialists.

\section{Learning points}

- Common causes of a single swollen extremity includes skin and soft-tissue infection, trauma and deep vein thrombosis and must be considered especially in patients with history of intravenous drug use (DU), however, puffy hand syndrome is a lesser-known complication of intravenous DU that may present similarly.

- Pathophysiology of puffy hand syndrome involves sclerosis and damage of veins and lymphatic vessels after repeated drug injections, leading to lymphoedema.

- Although puffy hand syndrome has not been specifically studied, treatments such as compression bandaging, compression and physical therapy used for lymphoedema may be beneficial.

Contributors YA, JD and ES were all equally involved in the care of this patient as well as in the synthesis, drafting and editing of this manuscript.

Funding The authors have not declared a specific grant for this research from any funding agency in the public, commercial or not-for-profit sectors.

Competing interests None declared.

Patient consent for publication Obtained.

Provenance and peer review Not commissioned; externally peer reviewed.

\section{REFERENCES}

1 Amode R, Bilan P, Sin C, et al. Puffy hand syndrome revealed by a severe staphylococcal skin infection. Case Rep Dermatol Med 2013:2013:1-2.

2 Andresz V, Marcantoni N, Binder F, et al. Puffy hand syndrome due to drug addiction: a case-control study of the pathogenesis. Addiction 2006:101:1347-51.

3 Arrault M, Vignes S. [Puffy hand syndrome in drug addiction treated by low-stretch bandages]. Ann Dermatol Venereol 2006:133:769-72.

Copyright 2018 BMJ Publishing Group. All rights reserved. For permission to reuse any of this content visit

https://www.bmj.com/company/products-services/rights-and-licensing/permissions/

BMJ Case Report Fellows may re-use this article for personal use and teaching without any further permission.

Become a Fellow of BMJ Case Reports today and you can:

- Submit as many cases as you like

- Enjoy fast sympathetic peer review and rapid publication of accepted articles

- Access all the published articles

- Re-use any of the published material for personal use and teaching without further permission

For information on Institutional Fellowships contact consortiasales@bmjgroup.com

Visit casereports.bmj.com for more articles like this and to become a Fellow 